DOI 10.37882/2223-2982.2021.09.31

\title{
МЕДИЙНЫЙ ДИСКУРС КАК ПРОДУЦЕНТ НОВОЙ РЕАЛЬНОСТИ: ПРАГМАТИЧЕСКИЙ И ЛИНГВИСТИЧЕСКИЙ АСПЕКТЫ
}

\section{MEDIA DISCOURSE AS A PRODUCER OF NEW REALITY: PRAGMATIC AND LINGUISTIC ASPECTS \\ O. Starodubova \\ A. Pervanyuk}

Summary: In the context of globalization, digitalization of society, media centrism is becoming the main attribute of the era, in connection with which the mass media model individual segments of eventfulness, which form a new picture of the world, the cognitive paradigm of society. Interpretive reality, produced by media discourse using various mechanisms at the pragmatic and linguistic levels, becomes the only source of information for the recipient and actually displaces, replaces reality. Thus, the mass media are not so much a mediator between eventfulness and the recipient of information, but rather a producer of a new reality that is formed in the process of linguo-cognitive modeling. Modeling tools are various linguistic resources, one of which is the subject nomination. The study revealed that the category of the subject is one of the key resources for modeling the manipulative strategy of conflictgenerating discourse. Knowledge of the mechanisms of its formation will allow the recipient to objectively evaluate the information presented by the media, not to react to manipulative tactics and to reveal the author's key intention as a generalized subject.

Keywords: media discourse, pragmatic and linguistic aspects, category of the subject, world picture, linguo-cognitive modeling.

\author{
Стародубова Ольга Юрьевна \\ К.филол.н., дочент, Московский государственный \\ лингвистический университет \\ oystarodubova@mail.ru \\ Перванюк Александра Васильевна \\ Аспирант, Московский государственный \\ лингвистический университет \\ alexxandra1@mail.ru
}

Аннотация: В условиях глобализации, цифровизации общества основным атрибутом эпохи становится медиацентризм, в связи с чем массмедиа моделируют отдельные сегменты событийности, из которых складывается новая картина мира, когнитивная парадигма общества. Интерпретативная реальность, продуцируемая медийным дискурсом при помощи различных механизмов на прагматическом и лингвистическом уровнях, становится единственным источником информации для реципиента и фактически вытесняет, подменяет действительность. Таким образом, массмедиа являются не столько посредником между событийностью и реципиентом информации, сколько продуцентом новой реальности, формирующейся в процессе лингвокогнитивного моделирования. Средствами моделирования выступают различные языковые ресурсы, одним из которых является субъектная номинация. В ходе исследования выяснилось, что категория субъекта - один из ключевых ресурсов моделирования манипулятивной стратегии конфликтогенного дискурса. Знание механизмов его формирования позволит реципиенту объективно оценивать информацию, преподносимую СМИ, не реагировать на манипулятивные тактики и выявлять ключевой замысел автора как генерализованного субъекта.

Ключевые слова: медийный дискурс, прагматический и лингвистический аспекты, категория субъекта, картина мира, лингвокогнитивное моделирование.

реального, который современные философы называют виртуальным [3, 11], квазиреальным [10, 12]. Происходит «конструирование реальности средствами массовой коммуникации. Средства массовой коммуникации формируют свое, мифологическое пространство» [4; 27].

\section{Языковые и прагматические механизмы продуширования текстово-Аискурсивной информашии массмехиа}

Массмедиа из инструмента интерпретации реальности трансформируется в ресурс манипулирования, конструирования новой реальности. Дескриптивная функция медийного дискурса вытесняется прескриптивной, императивной, предписывающей поведенческие модели Я-центризма. Медийный дискурс (конфликтогенный, манипулятивный сегмент) репрезентирует основные черты культуры и цивилизации в динамике [14]. Используя имеющиеся ресурсы языка и культуры, медиасфера моделирует в сознании массового реципиента мир, отличный от
Наиболее очевидно в медийном пространстве проявляется воздействие на человека языковых и прагматических механизмов, имитирующих и вытесняющих реальность экстралингвистическую. Через вербальную эксплицитную и имплицитную репрезентацию создается медиакартина мира, которая становится единственной реальностью для реципиента и совпадает с языковой картиной мира, представленной в медийном дискурсе. 
Конкретными манипулятивными механизмами формирования конфликтогенности становятся, вопервых, на прагматическом уровне - затекстовое моделирование событийности, сопряженное с выборкой фрагментов события, формирующих нужный ракурс восприятия целого. Во-вторых, собственно языковое моделирование конфликтогенности, которое представляет собой вербализацию интенции: номинация конфликтных субъектов с актуализацией различных идентичностей и т.д.

Таким образом, наиболее активную позицию в этом плане занимает категория субъектной организации текста как механизма моделирования картины мира читателя $[14,15]$. Одним из важнейших утверждений в когнитивной лингвистике является то, что язык не описывает окружающий мир, а моделирует его, то есть формирует картину мира его носителя. В когнитивной лингвокультурологии механизмы смыслопорождения, эксплицированные в тексте, рассматриваются с точки зрения национально-культурной детерминированности языкового сознания [8]. Текст является отражением языковой личности автора, эпохи и ментальности народа.

Согласно концепции М. Бахтина, текст всегда диалогичен, т.е. в процессе его концептуализации задействован как автор, так и читатель [2]. В процессе декодирования смысла и конструирования текстовой модели, выстраивается вторичная лингвокогнитивная модель. Авторскую текстовую модель читатель воспринимает через призму когнитивной парадигмы своей эпохи, в процессе формирования которой при помощи массмедиа происходит коррекция базовых ценностей, картины мира. В результате этого создается новый вариант, подводящий «итоги особого периода в концептуализации и категоризации выбранного в нем фрагмента мира» [9; 23]. При этом реальная картина мира отражается в ментальности человека в виде системы концептов, эксплицируемых в языке.

Теоретическая значимость исследования заключается в разработке малоисследованного сегмента сопоставления типов субъекта как носителя концептуальной информации в пределах медийного текста.

Практическая значимость исследования состоит в том, что, зная механизмы продуцирования манипулятивного сегмента медиадискурса, читатель сможет критически, аналитически воспринимать текстово-дискурсивную информацию, выявлять авторский замысел при помощи анализа субъектной организации текста и субъектных номинаций и более объективно понимать преподносимую информацию.

В исследовании использованы следующие методы: лингвокогнитивный, когнитивно-дискурсивный, описательный метод, метод контекстуального исследования и т.д.

\section{Категория субъекта и ее коншептуальные смыслы в медийном Аискурсе как механизм порожАения конфликтогенности}

Смыслообразующим фактором медийного поликодового эксплицитного и имплицитного пространства становится категория субъекта с набором идентичностей, образующих иерархическую картину мира, необходимая составляющая которой проецируется в соответствующее событийное поле при помощи различных языковых ресурсов и, обладая перлокутивной силой, формирует модель восприятия реальности [14]. В конце 20 века американский психолингвист Д. Слобин указывал на манипулятивный аспект медийного слова: «очень опасно людям забывать о том, что языки могут действительно влиять на то, во что они верят, и что они будут делать» $[13 ; 115]$.

Обратимся к примерам, иллюстрирующим различные механизмы конструирования конфликтогенной картины мира в медийном дискурсе. В качестве материала рассмотрим опубликованную 9 декабря 2020 года в № 136 Новой газеты статью «Станет ли убийца французского учителя народным героем Чечни?», подзаголовок - «Анзоров отрезал голову незнакомому человеку. На его похороны собралась толпа» [16]. Публикация стала отражением общественного отклика на события 16 октября 2020 года - убийство французского учителя Самюэля Пати.

Уже в самом заголовке, задавая вопрос, автор допускает, что данное явление может произойти. В предложении присутствуют три субъектные номинации. В отношении погибшего субъектная номинация указывает на его национальную, профессиональную и гендерную идентичности, в то время как в отношении преступника используются две контрастные субъектные номинации, указывающие на противоположные друг другу социальные идентичности, за счет чего формируется ирония, которая становится средством жесткой критики со стороны автора и моделирует конфликт. «Убийца» является прямой резко критической номинацией, указывающей только на социальный статус, в то время как учитель является носителем концепта национального героя и имеет глубоко положительный коннотацию.

Далее следует лид «Анзоров отрезал голову незнакомому человеку. На его похороны собрались толпы» [16]. Мы можем наблюдать анафорическую когезию, то есть в первом предложении присутствует прямая номинация субъекта «Анзоров», тогда как во втором автор использует местоимение. «Незнакомому человеку» - автор выбирает максимально широкую и обезличенную номина- 
цию, преподнося события в рамках почти обыденного. Однако он подразумевает, что стать жертвой подобного инцидента может каждый, а преступник не обязательно может быть нам известен. Таким образом журналист вовлекает читателя в данное событие. Номинация «Толпы» является генерализованным субъектом, в котором человек лишается своей личности.

Исследуемый текст является креолизованным - на первый план выводится скриншот из видео с похорон Абдуллы Анзорова.

«...на провластных чеченских аккаунтах в инстаграме ...доставлен труп 18-летнего этнического чеченца Абдуллы Анзорова, который ... зарезал школьного учителя истории Самюэля Пати.» [16]. Используя номинацию «провластные чеченские аккаунты», автор выражает свою критическую оценку не только по отношению к самим аккаунтам, но и к властям. Далее используется эксплицитные средства выражения субъекта: указывается его возрастная, национальная, гендерная и прямая идентичности, а именно имя и фамилия. «Труп» же является атрибутивным средством субъектной номинации. В отношении учителя детализируется его профессиональная идентичность, а также присутствует прямая номинация - имя и фамилия.

«После убийства Анзоров в лучших традициях ИГИЛ (запрещенная в России террористическая организаичия. - Ред.) выложил в собственный твиттер фотографию отрезанной головы учитель» [16].

Журналистом используется конструкция «в лучших традициях», выражающая сарказм и глубокое осуждение. В отношении террористической организации используется обязательная рамочная конструкция, являющаяся средством осуждения со стороны государства, а также напоминания о ее запрете и последующем наказании в случае нарушения данного запрета. В рамочной конструкции задействованы средства супраграфемики - текст выделен курсивом. Ресурсы метаграфемики (шрифт, размер букв, расположение фрагментов текста, цветовые выделения) также используются в качестве механизмов конструирования нужных автору смыслов [1].

Аббревиатура ИГИЛ является номинацией генерализованного субъекта, объединяющего всех членов данной террористической организации. Образ Анзорова уподобляется образам боевиков за счет синтагматики, а также отождествления их действий. "Oтрезанная голова» является атрибутивной номинацией. С помощью номинаций «молодой парень» и «совершенно незнакомый ему человек», автор приравнивает исходные обстоятельства к обыденным, а действия Анзорова к абсурдным, называя их «дикими».
«Судя по всему, «мститель» не знал ничего ни о своем пророке, ни о собственной религии и вряд ли читал что-то, кроме интернет-пабликов. По крайней мере главную книгу мусульман - Коран - Анзоров совершенно точно не читал. Он действовал как зомби, которому промыли мозги» [16].

В первом предложении журналист называет Анзорова «мстителем», используя кавычки (средство синграфемики), что придает ироничный оттенок данной номинации субъекта. Имплицитно автор создает в сознании читателя пространство для более «подходящих» номинаций, а также намекает, что, вероятно, Анзоров думал о себе как о мстителе. Номинацией «свой пророк» в предложении также подчеркивается ироничность, что является средством выражения критического отношения автора. Во втором предложении задействованы все средства метаграфемики: оно выделено в рамочную конструкцию (топографемика), шрифт имеет больший размер по отношению к остальному тексту. Чтобы выделить «Коран» в предложении, автор окружает слово с двух сторон тире, задействуя средства синграфемики, что сигнализирует об уважительном отношении автора. В данном отрывке убийца дискредитируется как последователь ислама. Автор имплицитно обвиняет его в поверхностности и примитивности суждений.

Субъектная номинация «зомби» является концептуальной метафорой - еще одним средством выражения авторской модальности. Сфера-источник концептуальной метафоры - неживое тело, труп. Сфера-мишень отсутствие рассудка, управляемость. Таким образом, автор указывает на то, что Анзоров стал жертвой чужих идеалов, виной чему «интернет-паблики». «Промыли мозги» является грубо-просторечной формулировкой, поддерживающей значение концептуальной метафоры. Субъект в данном случае опускается, однако подразумевается имплицитно.

Образ Анзорова отождествляется с «тысячами молодых людей со всего света, откликнувшихся на идею воссоздания исламского халифата», таким образом автор обозначает группу риска, указывая на их возрастную идентичность. Также автор осуждает отождествление ислама с терроризмом, именуя тех, кто так считает «не очень умными людьми», то есть ставит под вопрос их интеллектуальную состоятельность. Любые идентичности, кроме биологической, в данном случае отсутствуют.

«Полтора месяца семья Анзорова ждала выдачи тела. $B$ отличие от российских властей, чья позичия по поводу трупов террористов вполне однозначна (и чеченскими властями поддерживается), франиузские власти в таких вопросах более мягкие» [16]. 
«Семья» является нейтральной субъектной номинацией. В данном отрывке присутствую такие генерализованные субъекты как российские, чеченские и французские власти. Журналист как затекстовый субъект не выказывает своего личного отношения к политике властей в данном вопросе, однако указывает на тенденции и противопоставляет их. Зачастую в публицистике используется эвфемизм слову «труп» - «тело», особенно это касается жертв, к которым журналист пытается вызвать сострадание со стороны читателя. Номинация «труп» обладает большей атрибутивностью, и в данном случае автор выбирает именно ее в отношении к погибшим террористам.

«Видеоролики с траурной прочессией, в которой участвуют в основном молодые мужчины, уже появились в интернете» [16]. Акцентируя внимание на присутствии большого количества молодых людей, автор формирует опасение у читателя, а также моделирует образ потенциального террориста с помощью указания на его возрастную и гендерную идентичности.

«Решение похоронить террориста Анзорова на исторической родине, полагаю, появилось не без одобрения властей Чечни. Во всяком случае, без их согласия тут точно не обошлось» [16]. Автор больше не намекает на причастность Анзорова к террористам, а прямо использует данную номинацию. Предложения связаны с помощью анафорической когезии: власти Чечни - их. «Власти Чечни» - генерализованный субъект.

«... информацию о переименовании одной из улиц в Шалажах в честь 18-летнего головореза. ... в республике ... велась подготовка к похоронам Абдуллы Анзорова и активно шли разговоры о переименовании в его честь одной из улиц. Во многом это вина главы Чечни ...» [16]. Теперь автор выбирает более выразительные средства номинации в отношении убийцы. Следом за «террористом» он называет его «головорезом», что также выражает критическую оценку со стороны журналиста. Если в начале абзаца автор лишь намекает на заигрывание властей Чечни с чеченскими террористами, то к концу абзаца он прямо обвиняет в этом главу республики.

Для номинации Рамзана Кадырова автор использует ндикацию социального статуса, называет его «главой Чечни», а впоследствии использует прямую номинацию, выводя на передний план не социальный статут, а саму личность. Задействованы ресурсы топографемики и супраграфемики: первая половина предложения выделена, а шрифт увеличен: «По сути, Рамзан Кадыров возложил ответственность за преступление на его жертву, учителя Самюэля Пати...»[16]. В данном случае с помощью субъектной номинации журналист подчеркивает неправоту и абсурдность суждений Кадырова, а также провоцирует возмущение у читателя, однако далее становится известно, что причиной данному суждению являются конфликтные отношения между французскими и чеченскими властями. Для описания конфликта автором используется концептуальная метафора «все «зло» западного мира», а также языковая игра «религией которого является слово свободное, а не божье» [16].

«Как ни странно, Кадыров нашел в этот раз поддержку даже у тех чеченцев, которые ненавидят его, считая российским ставленником, ответственным за репрессии в отношении жителей республики» [16]. Важную роль играет подача фактов. В данном случае автор решает важным упомянуть о противниках Кадырова и их обвинениях, что опять же формирует негативное отношение читателя по отношению к главе Чеченской республики.

«Но можно ли осуждать внесудебные расправы над людьми и одновременно одобрять внесудебные расправы над ними? Получается, можно, если в первом случае это чеченцы, а во втором - французские журналисты и учитель» [16]. Автор задает риторический вопрос, умышленно нарушая законы логики, а именно закон противоречия, однако, сразу же дает ответ с помощью противопоставления субъектов в соответствии с концептуальной оппозицией свое - чужое, при этом данная оппозиция противоположна для Кадырова и для автора, так как сам Кадыров преподносится в соответствии с данной оппозицией как «чужое». С помощью риторического вопроса автор имплицитно обвиняет Кадырова в лицемерии, а именно в доминировании в его системе ценностей национального аспекта перед общечеловеческим.

«...nраво на жизнь либо действует для всех, либо не действует в принципе...» [16]. В этом фрагменте автор прямо выражает свою точку зрения, преподнося ее как неоспоримую истину. Он становится носителем базовых ценностей, для которого человеческая жизнь важна, вне зависимости от национальной принадлежности. Также используется субъектная номинация «все», что является генерализованным субъектом, объединяющим всех людей.

«Вообще с этими похоронами чеченское руководство само себя поставило в крайне неудобное положение. С одной стороны, именно власти в Чечне возвели Абдуллу Анзорова в ранг «национального героя». С другой стороны, они не могли допустить превращения его похорон в стихийный флешмоб республиканского маситаба, как это уже было в Чечне два года назад, когда ... хоронили еще одного «национального героя» убийцу полковника Буданова Юсупа Темирханова» [16]. Ответственность за создание положительной репутации убийцы среди чеченцев автор открыто возлагает 
на «чеченское руководство». Языковым средством в данном случае выступает стертая метафора «возвести в ранг», а также субъектная номинация «национальный герой». Журналист использует тактику гиперболизации, а также контрастную по семантике лексику («похороны» и «стихийный флешмоб республиканского масштаба») в целях создания иронии, а соответственно критики происходящего.

Далее автор рассматривает похожий инцидент и также именует убийцу «национальным героем». Кавычки как средство синграфемики выражают авторскую модальность, а именно жесткую критику. Несмотря на критику по отношению к чеченским властям и тем, кто прославляет убийц, автор пытается найти объяснение этому явлению именно в похожем инциденте. Используется аналогичная концептуальная метафора - так же как президент Франции «олицетворяет в глазах Кадырова всё «зло» западного мира», так и «Буданов в глазах чеченского народа - воплощение российского имперского «зла»» [16].

С помощью средств метаграфемики выделен абзац: «Возможно, если бы Буданова и других военнослужащих в России судили за все совершенные преступления, то чеченцы сегодня не идеализировали бы убийц и не нуждались бы в мстителях» [16].

В данном случае журналист высказывает свое личное предположение относительно причин и последствий сложившейся ситуации с помощью конструкции условного предложения. Субъект «чеченцы» выступает в концептуальной оппозиции как «свое», а имплицированный генерализованный субъект российских властей, военнослужащие и Буданов как «чужое».

«... И тогда ИГИЛ не пополнился бы чеченской молодой кровью. И учитель истории Самюэль Пати был бы жив. И Абдулла Анзоров тоже был бы жив» [16]. Фраза «Чеченской молодой кровью» является метонимией или же атрибутивной субъектной номинацией, отображающей национальную и возрастную идентичности. «Пополняться кровью» - концептуальная метафора. Сфера источник - биология, сфера мишень - примыкание к террористической организации. Автор использует прием парцелляции. Приводятся прямые субъектные номинации, а предложения, в которых они используются, имеют аналогичную грамматическую структуру, за счет чего оба субъекта становятся равнозначны. Таким образом, Анзоров сам становится жертвой наравне с Самюэлем Пати. За счет местоимения «мы» реализуется прием интимизации.

Как уже было сказано, основываясь на оценке автора, каждый субъект занимает свое место в концептуальной оппозиции свое - чужое, однако восприятие читателя способно вносить свои коррективы, так как в концептуализации текста участвуют оба затекстовых субъекта. В данной аналитической заметке количество субъектных номинаций, относящихся к «чужому» гораздо выше, чем относящихся к «своему», что связано с тематикой статьи. В результате частого использования данных субъектных номинаций возрастает ее конфликтогенность.

Одни и те же субъекты могут менять свое место в данной оппозиции в зависимости от хода мысли автора. Так, чеченские власти имеют положительную коннотацию во время упоминания об оцеплении села во время похорон, однако далее автор жестко критикует политику чеченского руководства по отношению к убийцам и террористам. Или же вначале автор критикует жителей Чечни за симпатию к убийцам и террористам, однако в конце статьи он приводит причины данного явления. Чеченцы противопоставляются российским военным преступникам и российским властям, на фоне чего субъект «чеченцы» становится носителем концепта «свое», гуманистических ценностей.

На фоне анализа категории субъекта как средства выражения авторского замысла можно прийти к выводу о том, что в аналитической статье автор как затекстовый субъект максимально активен. Он не просто излагает факты, а сопоставляет их и проводит анализ. Автор имеет свою гражданскую позицию и пытается донести ее до читателя. В статье раскрываются несколько конфликтов. Автор выносит конфликт из плоскости ислам - светское общество в плоскость терроризм - остальной мир, с помощью чего снижает риск возникновения исламофобии. Это происходит за счет резкого разграничения ислама и терроризма, положительного отношения со стороны журналиста к первому и отрицательного ко второму.

Автор критикует российские власти, сочувствующих террористам чеченцев, Рамзана Кадырова и руководство Чечни. Также упоминаются конфликты между Эмманюэлем Макроном и Рамзаном Кадыровым, Рамзаном Кадыровым и его противниками из Чечни, Рамзаном Кадыровым и Дмитрием Песковым, правительством Чечни и несогласным с ним населением, Юрием Будановым и чеченским населением, российскими военнослужащими и чеченцами, ИГИЛ и остальным миром. Следовательно, можно говорить о том, что конфликтогенность текста крайне повышена, а количество задействованных субъектов значительно.

\section{Выво}

Таким образом, категория субъекта является активным ресурсом формирования конфликтогенного и манипулятивного дискурса, т.к. пронизывает текст 
на всех этапах его существования: от момента создания до его потребления читателем. Механизмы моделирования манипулятивой стратегии используются журналистами в зависимости от политической и социальной направленности риторики издания и страны, что может способствовать нормализации обстановки в пределах определенной социальной группы, целого государства или же, напротив, усиливает социальную напряженность.

В системе субъектной организации текста отражаются все базовые ценности, концепты эпохи и этноса, что позволяет интерпретировать смысловые инварианты концептуальной оппозиции свое - чужое. Количество реальных субъектов выражено имплицитно и отличает- ся от количества эксплицированных в тексте субъектов. При этом немаловажную роль имеет интерпретационный коридор, так как читатель является соавтором и способен приращивать дополнительные смыслы. Событийность презентируется в ментальной деятельности индивида (автора и читателя) как система концептов, при этом интерпретацию смысла активирует слово, в частности вмонтированный автором в текст определенный языковой ресурс или прием (номинация событий прошлого и современности, а также интродукция и способы индикации статуса субъекта), который становится показателем культуры мышления пишущего и одновременно механизмом формирования когнитивной и коммуникативной грамотности реципиента, когнитивной парадигмы общества [15].

\section{ЛИТЕРАТУРА}

1. Аникаева А.А. Сущность графических невербальных средств в печатной рекламе / А.А. Аникаева. - Текст: непосредственный // Научные ведомости. Серия Гуманитарные науки. - 2011. - № 12 (107). Выпуск 10. - С. 186-191.

2. Бахтин М.М. Из черновых тетрадей / публикация В.В. Кожинова; подготовка текстов В.И. Словецкого // Литературная учеба, 1992. Кн. 5-6.

3. Богомолова Н.Н. Социальная психология массовой коммуникации: учеб. пособие для студентов вузов. - М.: Аспект Пресс, 2008.

4. Володина Л.В. Конструирование реальности средствами массовой коммуникации // Российская массовая культура конца XX века: материалы круглого стола, 4 декабря 2001 г. Санкт-Петербург. СПб: Санкт-Петербургское философское общество. Вып. 15.

5. Добросклонская Т.Г. Вопросы изучения медиатекстов (опыт исследования современной английской медиаречи). 2-е изд., стер. М.: Едиториал УРСС, 2005.

6. Кара-Мурза С.Г. Манипуляция сознанием. М.: Изд-во: Эксмо, 2005. 832 с.

7. К Красных В.В. «Свой» среди «чужих»: миф или реальность? М.: Гнозис, 2003.375 с.

8. Красных В.В. Психолингвокультурология и когнитивная лингвокультурология // (Нео) психолингвистика и (психо)лингвокультурология: новые науки 0 человеке говорящем. М.: Гнозис, 2017. С. 183-261.

9. Кубрякова Е.С. В поисках сущности языка: вместо введения // Когнитивные исследования языка. Вып. IV: Концептуализация мира в языке. М.: Ин-т языкознания РАН; Тамбов: Издательский дом ТГУ им. Г.Р. Державина, 2009. С.11-24.

10. Мальковская И.А. Знак коммуникации: Дискурсивные матрицы. Изд. 3-е. М.: Издательство ЛКИ, 2008.

11. Миронов В.В. Трансформация культуры в пространстве глобальной коммуникации // Медиаскоп: электронный научный журнал. 2009. Вып. 2. URL: http://www.mediascope.ru/трансформация-культуры-в-пространстве-глобальной-коммуникации (дата обращения: 20.11.2020).

12. Павлова Е.Д. Средства массовой информации - инструмент скрытого воздействия на сознание: социально-философский анализ. - М.: Наука, 2007. 206 с.

13. Слобин Д., Грин Дж. Психолингвистика. Пер. с англ. Е.И. Негневицкой// под общ. ред. С предисловием А.А. Леонтьева. - М., 1976. - 115с.

14. Стародубова 0.Ю. Медийный дискурс и вторичное лингвокогнитивное моделирование. // Язык и речь в Интернете: личность, общество, коммуникация, культура: сборник статей IV Международной научно-практической конференции. Москва, РУДН, 29 апреля 2020 г.: в 2 т. / под общ. ред. А.В. Должиковой, В.В. Барабаша. - Москва: РУДН, 2020. С.277 - 284.

15. Стародубова 0.Ю. Когнитивные и коммуникативные аспекты культуры речи в медийном дискурсе на фоне прецедентного феномена. // Актуальные проблемы культуры речи» (26 апреля 2019 года, г. Москва, МГОУ) / отв. ред. И.С. Папуша. - М.: ИИУ МГОУ, 2019. с. 103-108.

16. https://novayagazeta.ru/articles/2020/12/07/88260-stanet-li-ubiytsa-frantsuzskogo-uchitelya-narodnym-geroem-chechni 